\title{
Deconvolution effect of near-fault earthquake ground motions on stochastic dynamic response of tunnel-soil deposit interaction systems
}

\author{
K. Haciefendioğlu \\ Ondokuz Mayıs University, Department of Civil Engineering, 55139 Samsun, Turkey \\ Correspondence to: K. Haciefendioğlu (hckemal@omu.edu.tr)
}

Received: 29 February 2012 - Revised: 3 April 2012 - Accepted: 3 April 2012 - Published: 24 April 2012

\begin{abstract}
The deconvolution effect of the near-fault earthquake ground motions on the stochastic dynamic response of tunnel-soil deposit interaction systems are investigated by using the finite element method. Two different earthquake input mechanisms are used to consider the deconvolution effects in the analyses: the standard rigid-base input and the deconvolved-base-rock input model. The Bolu tunnel in Turkey is chosen as a numerical example. As near-fault ground motions, 1999 Kocaeli earthquake ground motion is selected. The interface finite elements are used between tunnel and soil deposit. The mean of maximum values of quasistatic, dynamic and total responses obtained from the two input models are compared with each other.
\end{abstract}

\section{Introduction}

It is usually accepted that underground structures suffer less from earthquakes than superstructures. However, recent earthquakes as in the Kobe, Japan earthquake (EQE Summary, 1995; Sinozuka, 1995), Chi-Chi, Taiwan earthquake (Chen et al., 2002; Wang et al., 2001; Uenishi et al., 1999) and Kocaeli, Turkey earthquake (Hashash et al., 2001) caused extensive failure in tunnels. Underground structure damages were also observed in different earthquakes, such as 1976 Tangshan earthquake in China (Wang, 1985) and the Loma Prieta earthquake in USA (Schmidt and Hashash, 1998). It is obvious that the safety of mountain tunnels in seismically active areas is still an important issue to tunnel engineers. The studies relating to tunnels under the seismic effects are performed by various researchers in recent years (Kirzhner and Rosenhouse, 2000; Karakostas and Manolis,
2002; Gazetas et al., 2005; Hashash et al., 2005; Liu and Song, 2005; Pakbaz and Yareevand, 2005; Kouretzis et al., 2006).

It is clear from the literature review that the effect of earthquake ground motions on the underground structures was investigated by many researches. All of these studies were performed by deterministic methods. Almost all the studies except for the study performed by Kirzhner and Rosenhouse (2000) considered the earthquake motions theoretically acting at an infinite depth as a simplification. In this study the earthquake motion will be applied at a plane which is located under the bottom of the tunnel-soil deposit interaction system. For this purpose, two different earthquake input mechanisms are used to consider the deconvolution effect of the near-fault ground motions on the stochastic dynamic response of tunnel-soil deposit interaction systems: namely, the standard rigid-base input model (Model-I) and the deconvolved base-rock input model (Model-II) (Leger and Boughoufalah, 1989; Haciefendioglu, 2010).

In the standard rigid-base input model (Model-I), the earthquake motion that will be applied to the base of the tunnel-soil deposit interaction system, is an accelerogram which is recorded previously by a strong motion seismograph located at the soil surface. The obvious deficiency of ModelI is that the motions actually occurring at the base of the tunnel-soil deposit interaction system cannot be the same as those recorded at its free surface. Accordingly, in the model a correction must be made to overcome this deficiency by calculation of a modified base rock motion by deconvolution of the free-field surface.

Near-fault ground motions causing much of the damage in recent major earthquakes (Northbridge in 1994, Kobe in 
1995, Chi-Chi in 1999, Kocaeli in 1999) are characterized by pulse-like motions that expose the structure to a high input energy at the beginning of the record. The study of near fault earthquake ground motion characteristics is a very important topic for both seismological and engineering communities. For this reason, three earthquake ground motions are selected to determine the effect of the near-fault earthquake ground motions on the stochastic dynamic response of the tunnelsoil deposit systems.

The interaction effects between tunnel and soil deposits are also taken into account in this study. For this purpose two dimensional interface finite elements are used between the soil deposit and structure. This is achieved by programming this feature into the general purpose computer program for the stochastic dynamic analysis of structural systems subjected to random ground motion, SVEM (Dumanoğlu and Soyluk, 2002).

\section{Stochastic analysis formulation}

Since the formulation of the random vibration theory for the spatially varying ground motion is given previously by many researchers (Harichandran et al., 1996; Haciefendioğlu and Soyluk, 2011; Haciefendioglu, 2006), in this study, the final equations will be used directly without any derivation. The random vibration theory provides an approximate estimate of the mean of the absolute maximum response of the structure in terms of the power spectral density function and a coherency function. The free response can be decomposed into pseudo-static and dynamic parts, i.e., $z=z_{s}+z_{d}$ when there is a differential excitation at the supports. Assuming the stationary excitation, the total variance responses can be obtained from

$\sigma_{z}^{2}=\sigma_{z_{d}}^{2}+\sigma_{z_{s}}^{2}+2 \operatorname{Cov}\left(z_{s}, z_{d}\right)$

in which $\sigma_{z_{d}}^{2}$ and $\sigma_{z_{s}}^{2}$ are the dynamic and pseudo-static variances, respectively, and $\operatorname{Cov}\left(z_{s}, z_{d}\right)$ is the covariance between the dynamic and pseudo-static responses $z_{d}$ and $z_{s}$ (Harichandran et al., 1996).

Depending on the peak response and standard deviation $\left(\sigma_{z}\right)$ of $\mathrm{z}(\mathrm{t})$, the mean of maximum value, $\mu$, in the stochastic analysis can be expressed as

$\mu=p \sigma_{z}$

in which $p$ is a peak factor, which is a function of the time of the motion and the mean zero crossing rate (Der Kiureghian and Neuenhofer, 1991).

\section{Spatially varying ground motion model}

The seismic analysis and design of lifelines, such as earthfill dams, bridges, pipelines, require information about the spatial variability of the seismic ground motions at the supports of these extended structures. The spatial variability of ground motion may significantly affect the seismic responses and induce additional stresses in the structure. This variation causes internal forces due to quasi-static displacements. For uniform ground motion case, quasi-static displacements normally do not produce internal forces. Therefore, while analyzing large structures, the spatially varying earthquake ground motions should be considered and total displacements have to be used in expressing the governing equation of motion. Der Kiureghian and Neuenhofer (1991) identified three phenomena that are responsible for the spatial variation of the ground motion. In this study, the stochastic response of the underground structures when applied to the spatially varying ground motion is investigated. The site response effect is ignored in the analyses.

The spatial variability of the ground motion is characterized by the coherency function $\gamma_{l m}(\omega)$. In the case of a homogeneous soil site, the cross-power spectral density function between the accelerations $\ddot{u}_{g_{l}}$ and $\ddot{u}_{g_{m}}$ at the support points $l$ and $m$ is written as

$S_{\ddot{u}_{g_{l}}} \ddot{u}_{g_{m}}(\omega)=\gamma_{l m}(\omega) . S_{\ddot{u} g}(\omega)$

in which $\gamma_{l m}(\omega)$ is the coherency function and $S_{\ddot{u}_{g}}(\omega)$ is the power spectral density function of uniform surface and deconvolved ground accelerations. Recently, Der Kiureghian (1996) proposed a composite model of the coherency function as

$\gamma_{l m}(\omega)=\gamma_{l m}(\omega)^{i} \exp \left[i\left(\theta_{l m}(\omega)^{w}\right]\right.$

in which, $\gamma_{l m}(\omega)^{i}$ characterizes the incoherence effect (Harichandran, 1991), $\gamma_{l m}(\omega)^{w}$ represents the wave passage effect, and $\gamma_{l m}(\omega)^{S}$ defines the complex valued site response effect, respectively. For the incoherence effect, the model developed by Harichandran and Vanmarcke (1986) based on the statistical analysis of strong ground motion data from the SMART-1 dense array is considered.

\section{Application}

The Bolu tunnel is part of the Transit European Motorway in an area where squeezing rock masses occur. The crossing of the Bolu Mountain is included in the $120 \mathrm{~km}$ section between Gümüşova and Gerede. The last $25 \mathrm{~km}$ stretch, the most challenging, runs parallel to the North Anatolian Fault. This stretch, under construction, includes several viaducts and the Bolu tunnel. The Bolu tunnel is a $3360 \mathrm{~m}$ long twin bored three lanes tunnel. The average excavated radius is $8 \mathrm{~m}$, corresponding to an $\mathrm{x}$-section area between 190 and $260 \mathrm{~m}^{2}$. The width of the ground pillar between tubes varies from about $28 \mathrm{~m}$ at portals to almost $48 \mathrm{~m}$. Depths are up to $250 \mathrm{~m}$; on $86 \%$ of the total length, overburdens are higher than $100 \mathrm{~m}$ and on $48 \%$ higher than $150 \mathrm{~m}$. 


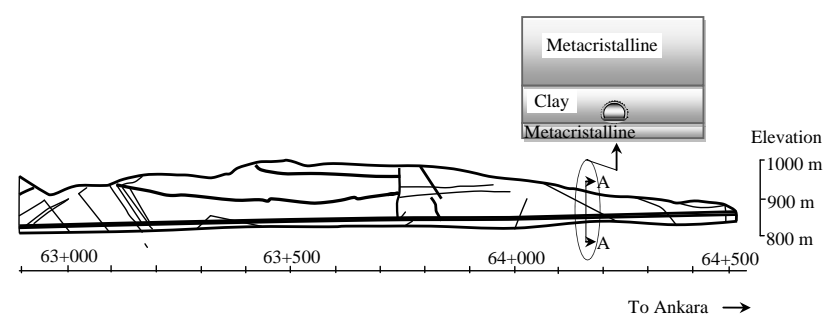

Fig. 1. Bolu Tunnel-longitudinal profile (Amberk and Russo, 2001).

Table 1. Material properties for A-A cross section of the Bolu Tunnel.

\begin{tabular}{llll}
\hline Materials & $\begin{array}{l}\text { Modulus of } \\
\text { Elasticity }\left(\mathrm{N} \mathrm{m}^{-2}\right)\end{array}$ & $\begin{array}{l}\text { Poisson's } \\
\text { Ratio }\end{array}$ & $\begin{array}{l}\text { Unit weights } \\
\left(\mathrm{kN} \mathrm{m}^{-3}\right)\end{array}$ \\
\hline Tunnel (Concrete) & $2.00 \mathrm{E} 10$ & 0.15 & 24.00 \\
Metacristalline & $2.67 \mathrm{E} 10$ & 0.24 & 26.38 \\
Clay & $1.77 \mathrm{E} 9$ & 0.45 & 20.30 \\
Interface Element & $1.40 \mathrm{E} 10$ & 0.25 & 24.00 \\
\hline
\end{tabular}

Bolu tunnel longitudinal profile is sketched and the lithology encountered is indicated in Fig. 1. A wide range of soils is represented, mainly highly tectonised series of mudstones, siltstones, limestones and fault gouge clays. The consistence of the soil varies from competent rock requiring blasting to very weak clayey zones where heavy advancement problems were encountered. A-A cross section at the Ankara portal is selected in order to investigate the stochastic response of the Bolu tunnel. The selected cross section details and finite element model of the tunnel with soil deposits are plotted in Fig. 2. The properties of the Bolu tunnel, the soil deposits surrounding the tunnel and interface elements between soil deposit and tunnel are given in Table 1 .

The tunnel-soil deposit interaction model subjected to random earthquake ground motions in the horizontal direction is presented Fig. 3. The horizontal input is assumed to travel across the tunnel-soil deposit system from the left to right with finite velocity of $2000 \mathrm{~m} \mathrm{~s}^{-1}$. First 15 modes and $10 \%$ damping ratio for the analyses are considered. Two translational degrees of freedom are assigned to each node and a plane-strain assumption is used in the calculations.

\section{Input ground motions}

The stochastic analysis of the Bolu tunnel is performed for random earthquake ground motion by taking into account the incoherence and wave passage effects. For this purpose, two different near-fault earthquake ground motions are considered in the analyses for the tunnel-soil deposit interaction system supports.

In this section, the 1999 Kocaeli near-fault earthquake ground motion record was selected as input motion, corresponding to station number IZT180. The time-history plot

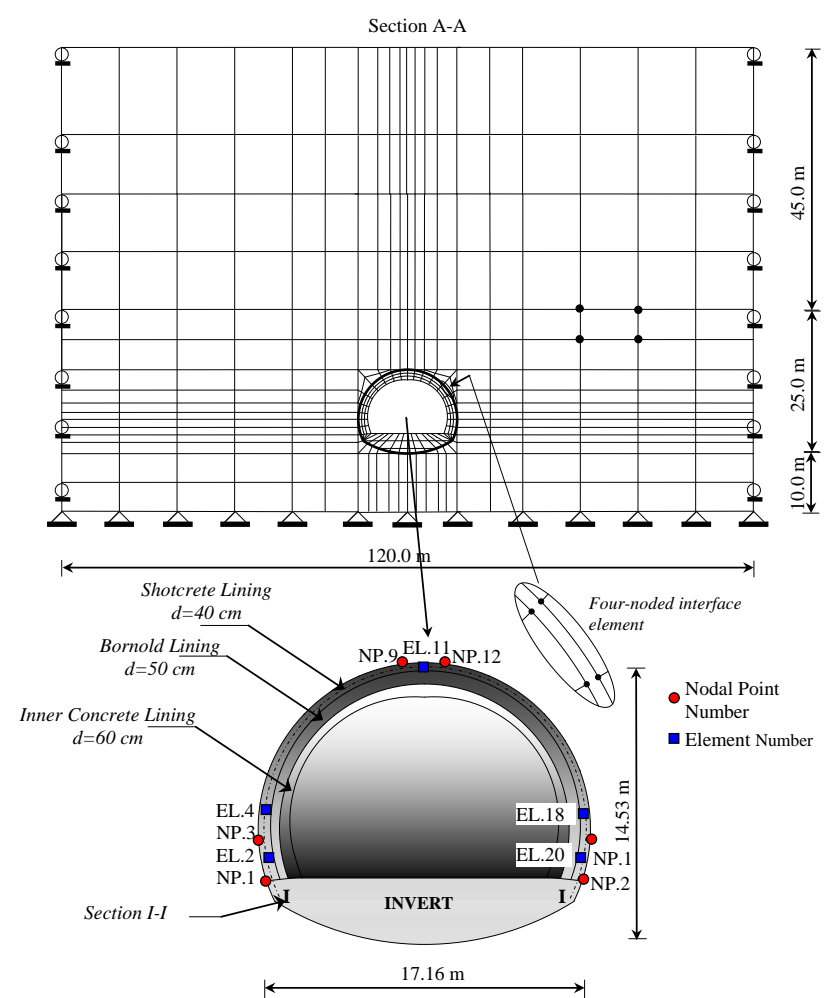

Fig. 2. Finite element model of the tunnel-soil deposit system and the detail of the Bolu tunnel for A-A cross section.

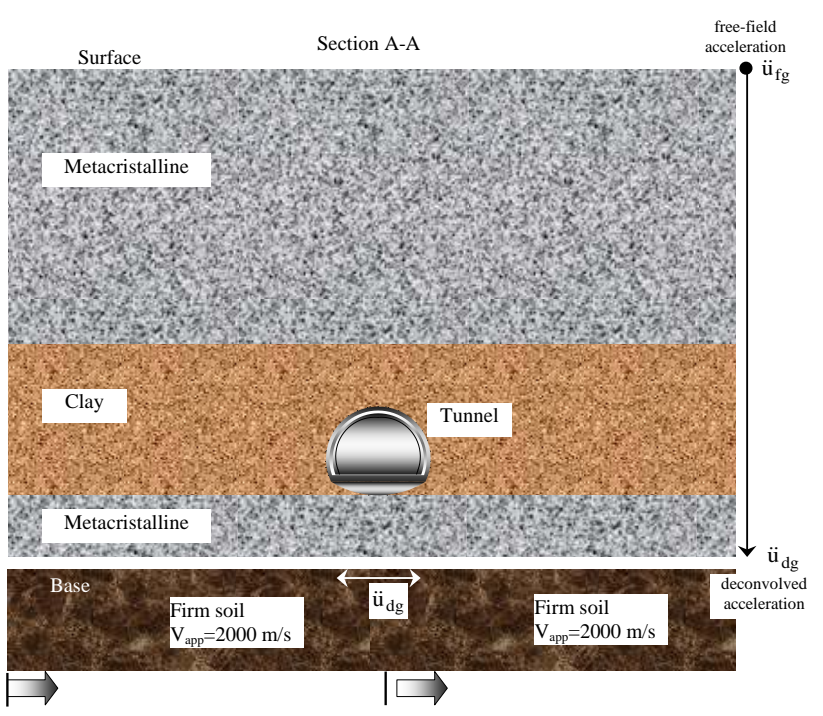

Fig. 3. Materials surrounding A-A cross section of the Bolu Tunnel to random earthquake ground motion.

of acceleration and velocities of Kocaeli earthquake record is depicted in Figs. 4 and 5, respectively. The strong motion records are obtained from the PEER Strong Motion Database (PEER, 2012). This database gives information about the site conditions and the soil types for the instrument locations. 


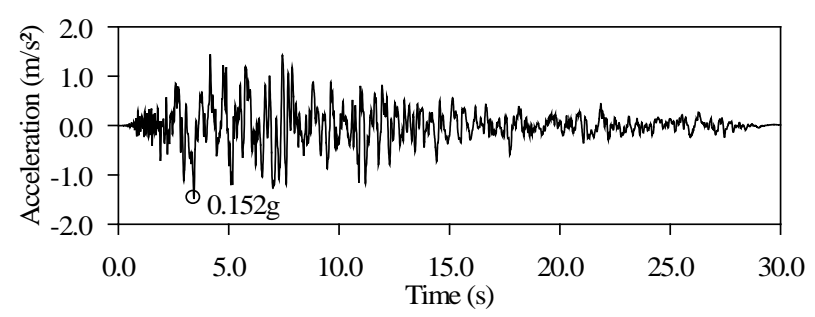

Fig. 4. Time-history of the near-fault earthquake ground motion acceleration for the 1999 Kocaeli earthquake.

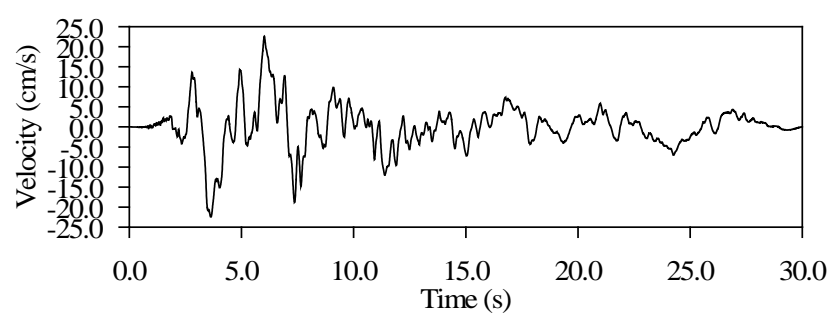

Fig. 5. Time-history of the near-fault earthquake ground motion velocity for the 1999 Kocaeli earthquake.

The properties of the selected near-fault earthquake ground motion records are indicated in Table 2. These near-fault earthquake ground motion records are recorded at firm soil site conditions.

The deconvolved accelerogram of the selected near-fault earthquake ground motions are calculated by using the computer program SHAKE91 (Idriss and Sun, 1992), which is based on one-dimensional wave propagation theory. The theory considers the responses associated with vertical propagation of shear waves through the linear viscoelastic system shown in Fig. 3. The soil system used for the deconvolution and simulation consists of one horizontal layer, which extends to infinity in the horizontal direction and has a half space as the bottom layer. Each layer is homogeneous and isotropic, and is characterized by the thickness, mass density, shear modulus and damping factor. The selected values of modulus reduction and damping factors versus shear strain for rock material is based on the expressions given in reference (Schnabel et al., 1972). The principal parameters in the analysis of the deconvolved accelerogram are the shear wave velocity and the damping ratio of the foundation soil. It should be noted that the accelerogram is affected by the shear wave velocity and the damping ratio of the foundation soil. The values of the shear wave velocity and the damping ratio of the foundation rock are selected as $2000 \mathrm{~m} \mathrm{~s}^{-1}$ and $10 \%$, respectively. The deconvolved time history of the Kocaeli near-fault earthquake ground motion is shown in Fig. 6. The acceleration and displacement spectral density function of the free-surface and deconvolved ground acceleration are depicted in Figs. 7 and 8, for the selected ground motion, re-

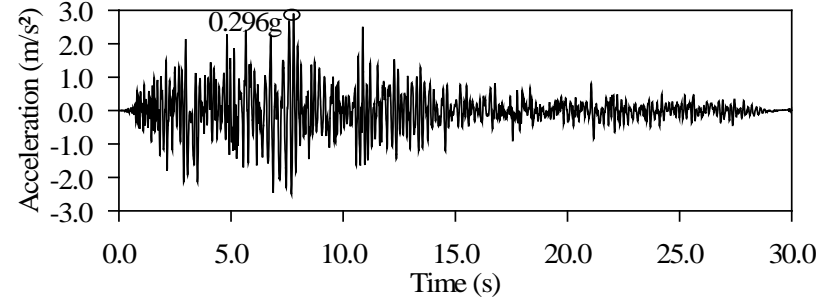

Fig. 6. Time-histories of the deconvolved ground motion accelerations for the 1999 Kocaeli earthquake.

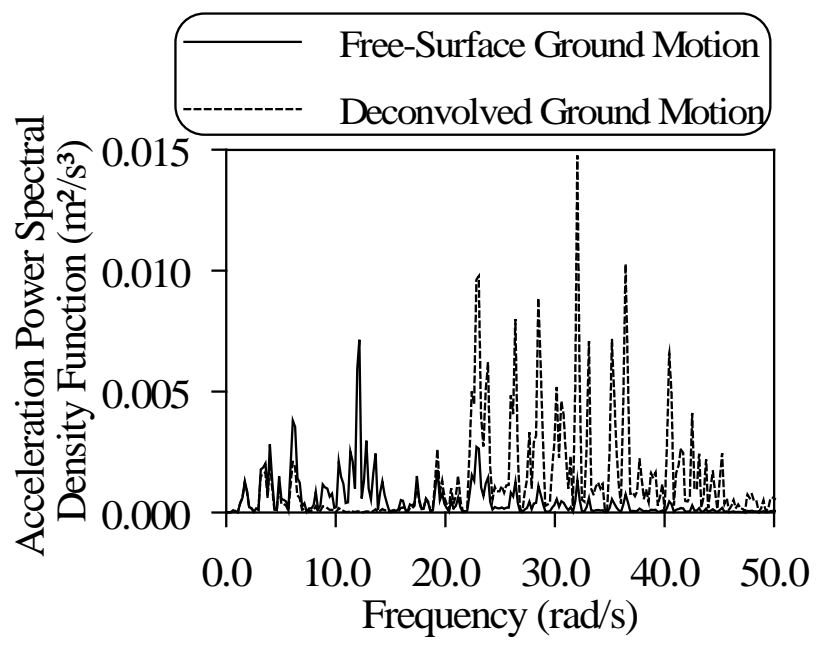

Fig. 7. Acceleration spectral density function of the free-surface and deconvolved ground acceleration for the 1999 Kocaeli earthquake.

spectively. It is apparent in Fig. 6 that local soil conditions considerably affect the frequency contents and amplitudes of the ground acceleration records and the deconvolved ground acceleration values become larger than the values recorded at the free-surface. However, as the acceleration spectral density function values obtained from Model-I are larger than those from Model-II at the low frequencies, they are smaller than those from Model-II at the high frequencies (Fig. 7).

\section{Displacements}

The horizontal displacements along the Section I-I (Fig. 2) of the tunnel are calculated for two earthquake input mechanisms: the standard rigid-base input model (Model-I) and the deconvolved-base-rock input model (Model-II). Two different near-fault earthquake ground motions are used to determine the effect of the base-rock characteristics on the stochastic response of the tunnel-soil deposit interaction system. The acceleration spectral density functions determined at the free-surface are used for input Model-I and those 
Table 2. Properties of a selected near-fault earthquake ground motion record.

\begin{tabular}{llllll}
\hline & \multicolumn{4}{c}{ Near-Fault Strong Ground Motions } \\
Earthquake & Magnitude (M) & PGA $\left(\mathrm{cm} \mathrm{s}^{-2}\right)$ & PGV $\left(\mathrm{cm} \mathrm{s}^{-1}\right)$ & Distance to the fault $(\mathrm{km})$ & PGV/PGA(s) \\
\hline Kocaeli & 7.4 & 149.11 & 22.60 & 4.80 & 0.15 \\
\hline
\end{tabular}

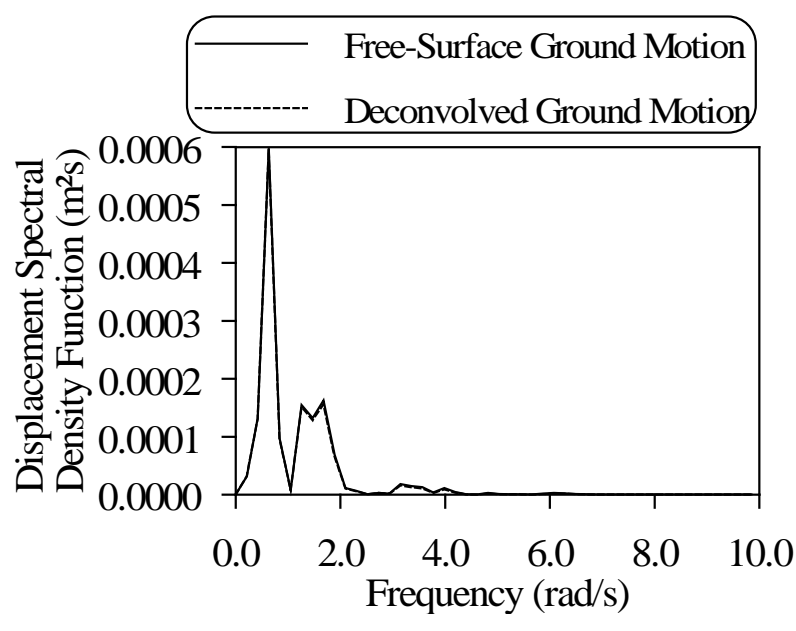

Fig. 8. Displacement spectral density function of the free-surface and deconvolved ground for the 1999 Kocaeli earthquake.

from the deconvolved accelerogram are considered for input Model-II (Fig. 6).

In order to investigate the effect of two different earthquake input mechanisms on the quasi-static, dynamic and total horizontal displacements, the mean of maximum values of horizontal displacements obtained along the Section I-I of the tunnel is depicted in Fig. 9a-c for the Kocaeli earthquake in 1999.

In these figures, it is observed that the quasi-static, dynamic and total displacement values obtained from Model-I are larger than those of Model-II for the Kocaeli earthquakes.

\section{Stresses}

The mean of maximum stress values of the tunnel are also calculated for two earthquake input mechanisms: the standard rigid-base input model (Model-I) and the deconvolvedbase-rock input model (Model-II). Two different near-fault earthquake ground motions are used to determine the effect of the base-rock characteristics on the stochastic response of the tunnel-soil deposit interaction system.

Section I-I shown in Fig. 2 is selected for the comparison of the mean of maximum quasi-static, dynamic and total horizontal, vertical and shear stresses. The stress components on Section I-I are depicted in Figs. 10-12 for the two earthquake input mechanisms mentioned before. The stresses due to the
Kocaeli earthquake are obtained at the center points of the finite elements.

Figures 10-12 illustrate the quasi-static, dynamic and total horizontal and vertical stresses induced by the Kocaeli earthquake. It is obvious that, while the stresses obtained from Model-I and Model-II for the quasi-static and total components are close to each other, the dynamic stresses obtained from Model-I are larger than those of Model-II. The mean of maximum quasi-static, dynamic and total shear stresses induced by the Kocaeli earthquake are shown in Fig.12. As the quasi-static stresses due to Model-I and Model-II are close to each other, the dynamic and total stresses obtained from Model-I are significantly larger than those of Model-II.

As defined in Eq. (1), the quasi-static component is dependent on the displacement spectral density function (Fig. 8). Because the variances of ground displacements determined by Model-I and Model-II for selected earthquakes ground motion are close to each other, it is natural to have nearly the same pseudo-static stresses.

\section{Conclusions}

In this paper, the deconvolution effect of the random nearfault earthquake ground motions on the stochastic dynamic response of tunnel-soil deposit interaction systems are investigated by using the finite element method. For this purpose, two different earthquake input mechanisms: namely, the standard rigid base input model (Model-I) and the deconvolved-base-rock input model (Model-II) are used. The response components, quasi-static, dynamic and covariance components, caused by the random near-fault earthquake ground motion are presented for two different earthquake input mechanisms. To investigate the effect of the near-fault earthquake ground motion on the stochastic dynamic behavior of the Bolu tunnel, 1999 Kocaeli earthquake ground motion is considered in the analyses.

The mean of maximum values of the quasi-static, dynamic and total displacements obtained for Model-I are larger than those of Model-II for the Kocaeli earthquake.

It is observed that as the quasi-static stresses induced by Model-I and Model-II are generally close to each other, the dynamic stresses induced by Model-I are generally larger than those of Model-II. As for the total stresses, the stresses due to Model-I have sometimes small or large values according to Model-II. It is thought that the reason for this situation 

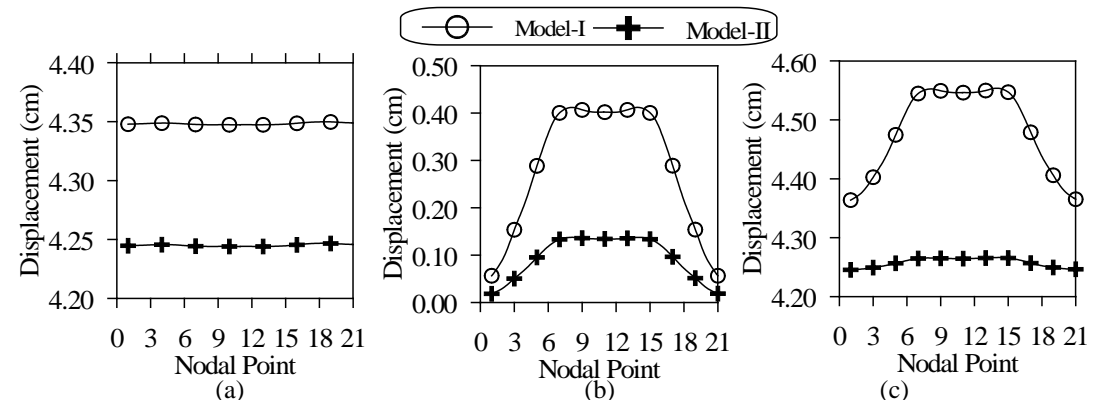

Fig. 9. Mean of maximum (a) quasi-static, (b) dynamic and (c) total displacements for the Kocaeli earthquake in 1999, respectively.

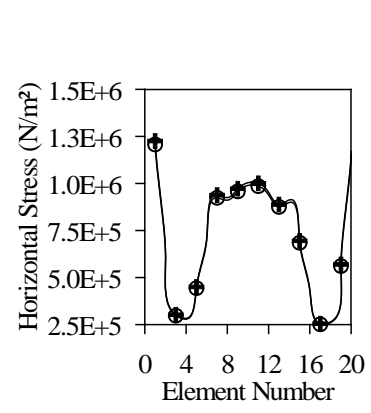

(a)

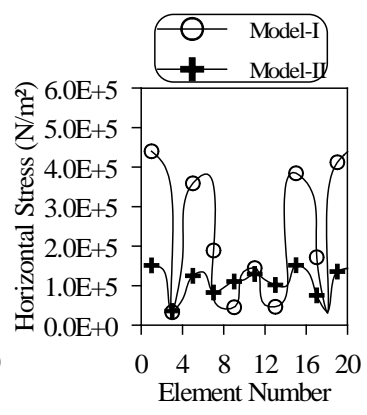

(b)

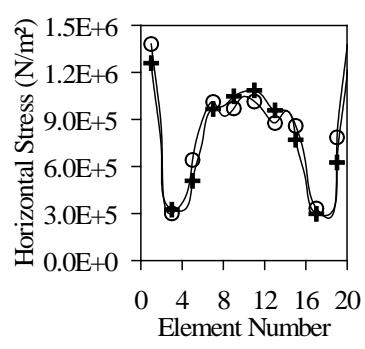

(c)

Fig. 10. Mean of maximum (a) quasi-static, (b) dynamic and (c) total horizontal stresses for the Kocaeli earthquake in 1999, respectively.

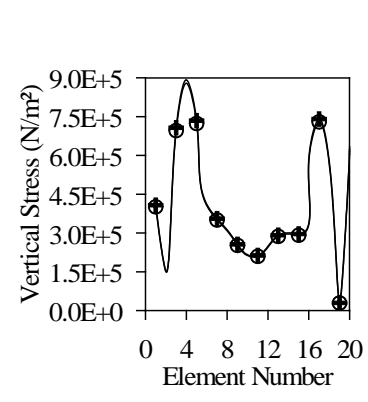

(a)

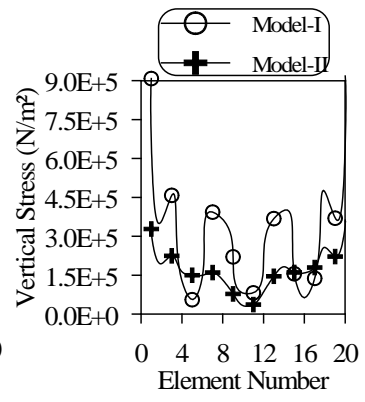

(b)

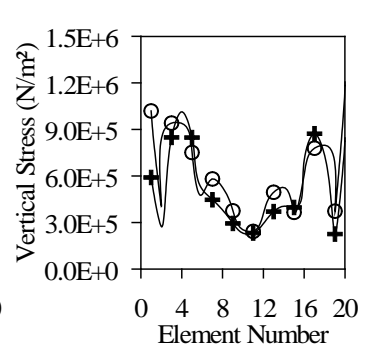

(c)

Fig. 11. Mean of maximum (a) quasi-static, (b) dynamic and (c) total vertical stresses for the Kocaeli earthquake in 1999, respectively.

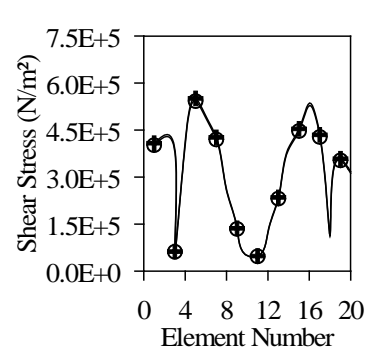

(a)

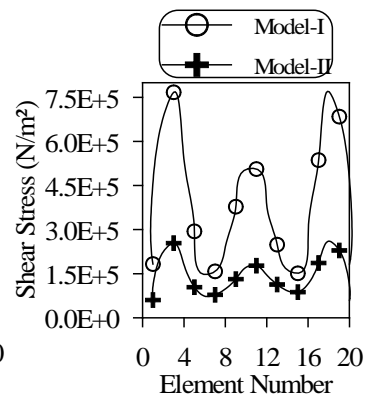

(b)

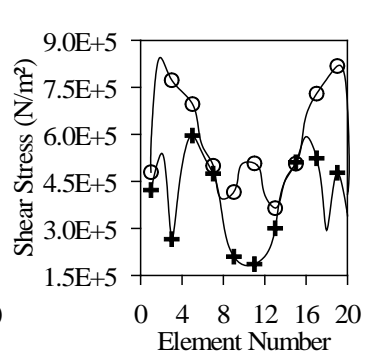

(c)

Fig. 12. Mean of maximum (a) quasi-static, (b) dynamic and (c) total shear stresses for the Kocaeli earthquake in 1999, respectively. 
is the characteristic properties of the near-fault earthquake ground motion.

It can be also observed that, while the pseudo-static response components are sensitive to the displacement spectral density functions of the ground motions, the dynamic response components are sensitive to the acceleration spectral density functions.

It can be concluded from these analyses that the standard rigid-base input model (Model-I) is inadequate to evaluate the stochastic dynamic response of tunnel-soil deposit interaction systems subjected to the random near-fault earthquake ground motions. For this purpose, the deconvolved-baserock input model (Model-II) should be used to obtain more accurate results in the analyses of underground structures.

Acknowledgements. This research was supported by Ondokuz Mayıs University.

Edited by: M. E. Contadakis

Reviewed by: H. B. Başağa and another anonymous referee

\section{References}

Amberk, W. and Russo, M.: Seismic design of underground structures the Bolu tunnel, Report No.102.2-R.133/12.37, Lombardi SA Engineering Limited, Switzerland, 2001.

Chen, W. W., Shih, B.-J., Chen, Y.-C., Hung, J.-H., and Hwang, H. H.: Seismic response of natural gas and water pipelines in the Ji-Ji earthquake, Soil Dyn. Earthq. Eng., 22, 1209-1214, 2002.

Der Kiureghian, A.: A coherency model for spatially varying ground motions. Earthquake Engineering and Structural Dynamics, 25, 99-111, 1996.

Der Kiureghian, A. and Neuenhofer, A.: A response spectrum method for multiple-support seismic excitations. Report No.UCB/EERC-91/08, Berkeley (CA), Earthquake Engineering Research Center, College of Engineering, University of California, 66 pp., 1991.

Dumanoğlu, A. A. and Soyluk, K.: SVEM: A stochastic structural analysis program for spatially varying earthquake motions, Turkish Earthquake Foundation, TDV/KT 023-76, 2002.

EQE Summary Report: The January 17, 1995 Kobe Earthquake, 1995.

Gazetas, G., Gerolymos, N., and Anastasopoulos, I.: Response of three Athens metro underground structures in the 1999 Parnitha earthquake, Soil Dynam. Earthq. Eng., 25, 617-633, 2005.

Haciefendioğlu, K.: Transient stochastic analysis of nonlinear response of earth and rock-fill dams to spatially varying ground motion, Struct. Eng. Mech., 22, 647-664, 2006.

Hacıefendioğlu, K. and Soyluk, K.: Nonlinear response of earthfill dams to spatially varying ground motion including site response effect, Adv. Struct. Eng., 14, 223-234, 2011.

Hacıefendioğlu, K.: Deconvolved stochastic seismic excitation effect on the nonlinear response of asphaltic lining dam-foundation interaction systems, Adv. Struct. Eng., 13, 127-137, 2010.

Haricandran, R. S. and Vanmarcke, E. H.: Stoc variation of earthquake ground motion in space and time, J. Eng. Mech., 112, 154$174,1986$.
Harichandran, R. S.: Estimating the spatial variation of earthquake ground motion from dense array recordings, Struct. Saf., 10, 219-233, 1991.

Harichandran, R. S., Hawwari, A., and Sweidan, B. N.: Response of long-span bridges to spatially varying ground motion, J. Struct. Eng., 122, 476-484, 1996.

Hashash, Y. M. A., Hook, J. J., and Schmid, J. I. C.: Seismic design and analysis of underground structures, Tunnelling and Underground Space in Technology, 16, 247-293, 2001.

Hashash, Y. M. A., Park, D., and Yao, J. I.-C.: Ovaling deformations of circular tunnels under seismic loading, an update on seismic design and analysis of underground structures. Tunnelling and Underground Space in Technology, 20, 435-441, 2005.

Idriss, I. M. and Sun, J. I.:SHAKE91: A Computer program for conducting equivalent linear seismic response analyses of horizontally layered soil deposits. Department of Civil and Environmental Engineering, University of California, Davis, 65 pp., 1992.

Karakostas, C. Z. and Manolis, G. D.: Dynamic response of tunnels in stochastic soils by the boundary element method, Engineering Analysis with Boundary Elements, 26, 667-680, 2002.

Kirzhner, F. and Rosenhouse, G.: Numerical analysis of tunnel dynamic response to earth motions, Seismic Analysis, 15, 249-258, 2000.

Kouretzis, G. P., Bouckovalas, G. D., and Gantes, C. J.: 3-D shell analysis of cylindrical underground structures under seismic shear (s) wave action, Soil Dyn. Earthq. Eng., 26, 909-921, 2006.

Leger, P. and Boughhoufalah, M.: Earthquake input mechanisms for time domain analysis of the dam-foundations systems, Eng. Struct., 11, 37-46, 1989.

Liu, H. and Song, E.: Seismic response of large underground structures in liquefiable soils subjected to horizontal and vertical earthquake excitations, Comput. Geotech., 32, 223-244, 2005.

Pakbaz, M. C. and Yareevand, A.: 2-D analysis of circular tunnel against earthquake loading, Tunnelling and Underground Space in Technology, 20, 411-417, 2005.

PEER (Pacific Earthquake Engineering Research Centre), http:// peer.berkeley.edu/, 2012.

Schmidt, B. and Hashash, Y. S. T.: US immersed tube retrofit, Tunnels Tunneling Int., 30, 22-24, 1998.

Schnabel, P. B., Lysmer, J., and Seed, H. B.: SHAKE: A computer program for earthquake response analysis of horizontally layered sites. Report No.EERC-72/12, Earthquake Engineering Research Centre, University of California, Berkeley, 1972.

Sinozuka, M.: The Hanshin-Awaji earthquake of January 17, 1995, performance of lifelines. NCEER-95-0015, 1995.

Uenishi, K., Sakurai, S., Uzarski, S. M.-J., and Arnold, C.: ChiChi Taiwan, earthquake of September 21, 1999: reconnaissance report, Earthquake Spectra, 5, 153-173, 1999.

Wang, J. M.: Distribution of earthquake damage to underground facilities during the 1976 Tang-shan earthquake, Earthq. Spectra, 1, 741-757, 1985.

Wang, W. L., Wang, T. T., Su, J. J., Lin, C. H., Seng, C. R., and Huang, T. H.: Assessment of damage in mountain tunnels due to the Taiwan Chi-Chi earthquake, Tunneling and Underground Space Technology, 16, 133-150, 2001. 